\title{
CARTAS MÁGICAS A 801 - O PIBID E A INTERDISCIPLINARIDADE
}

Talyta Teixeira Thoméi

Larissa Martins Pedro ${ }^{\text {ii }}$ Sônia Martins De March ${ }^{\text {iii }}$

Daniela Arns Silveira ${ }^{\text {iv }}$

Manuela Rossa de Souza ${ }^{v}$

\begin{abstract}
Resumo: O presente trabalho apresenta as experiências no PIBID de acadêmicas do curso de licenciatura em Letras - Língua Portuguesa na UNESC. Tal projeto, de caráter interdisciplinar, foi realizado na escola Pascoal Meller, em Criciúma, SC. Foi abordado com os alunos o gênero textual cartas, apresentando sua história, desenvolvimento e utilização, além de ter sido explanado os diversos tipos de cartas e outras curiosidades afins. O projeto teve como pano de fundo o universo de Harry Potter, garantindo aos encontros um pouco de ludicidade e dinâmica. Todo o projeto tinha como intuito produzir um saber plural e interdisciplinar, distanciando um pouco de muitas práticas escolares que acabam por prenderse em uma só esfera do conhecimento, deixando de criar pontes com as outras áreas do saber.
\end{abstract}

Palavras-chave: PIBID; Interdisciplinaridade; Cartas; Ludicidade.

\section{EPÍSTOLAS MÁGICAS AL 801 - PIBID E INTERDISCIPLINARIDAD}

Resumen: El presente trabajo presenta las experiencias en PIBID de académicos del grado en Letras - Lengua Portuguesa enla UNESC. Tal proyectointerdisciplinario se realizóenlaescuela Pascoal Meller, en Criciúma, SC. Se discutióel género textual epístolasconlosestudiantes, conlapresentación de suhistoria, desarrollo y uso, así como laexplicación de los diversos tipos de epístolas y otras curiosidades relacionadas. El proyectotenía como telón de fondoel tema de Harry Potter, asegurándoles a lasclasesun poco de diversión y dinámica. Todo elproyectoteníalaintención de producirunconocimiento plural e interdisciplinario, alejándoseun poco de muchasprácticas escolares que se fijanenun solo campo delconocimiento, sincrearpuentesconlasdemás áreas.

Palabras clave: PIBID; Interdisciplinariedad; Epístolas; Dinámica.

\section{Introdução}

Muito se tem discutido, recentemente, acerca do ensino interdisciplinar nas escolas. Várias são as teorias e práticas postuladas para a inserção desse método e é por esse motivo que o PIBID Interdisciplinar se faz importante como um projeto para a iniciação dos acadêmicos de licenciaturas das Instituições de Ensino Superior. Dessa forma, as acadêmicas do Curso de Letras da Universidade do Extremo Sul Catarinense, doravante UNESC, 
iniciaram o projeto interdisciplinar chamado "Cartas mágicas a 801" na escola Pascoal Meller, com alunos do oitavo ano.

O objetivo de tal projeto é, por meio de uma metodologia interdisciplinar, diversificada, lúdica e dinâmica, com a temática de Harry Potter, inserir um saber variado e de intersecção com as disciplinas, de forma a construir e contextualizar os aprendizados e torná-los mais úteis aos alunos. O tema trabalhado durante os encontros teve relação com o gênero textual cartas e o universo de Harry Potter, sendo abordado o contexto histórico, bem como curiosidades, utilização, produção e leitura de cartas. A justificativa do presente projeto é o fato de que o gênero cartas, não obstante à crença geral de que está em desuso, transfigura-se em outras formas - e-mails, mensagens, WhatsApp etc. -, sendo, portanto, atual.

Este artigo foi estruturado de maneira que explanasse, a princípio, sobre o PIBID e a interdisciplinaridade e, após, uma explicação geral do projeto, seguida da descrição dos encontros. Foi usado como bibliografia básica, no quesito interdisciplinaridade, os autores Fazenda (2002 e 2008) e Japiassu (2016), além de informações sobre o PIBID no website da Fundação Capes. Para os conteúdos abordados em sala de aula, as acadêmicas utilizaram informações de meios diversos - tais como livros, sites e filmes.

\section{PIBID}

O Programa Institucional de Bolsas de Iniciação à Docência, doravante PIBID, é uma iniciativa do Ministério da Educação, Fundação CAPES, a fim de oferecer bolsas para graduandos de licenciatura do Ensino Superior. Os alunos fazem partes de projetos que

devem promover a inserção dos estudantes no contexto das escolas públicas desde o início da sua formação acadêmica para que desenvolvam atividades didático-pedagógicas sob orientação de um docente da licenciatura e de um professor da escola. (BRASIL, 2008)

Diante disso, promove-se o aprendizado do acadêmico sobre a sua área de atuação, em contato, não somente com a teoria, mas com a prática em sala de aula, sob o auxílio/orientação de dois professores experientes. Ao mesmo tempo em que os professores aprendem com a execução dos acadêmicos que - quase sempre - apresentam uma didática 
diferente da utilizada por eles e sem se prender ao livro didático - ação essa que, muitas vezes, é o direcionador da aula do professor.

Esse programa é planejado para os cursos de licenciatura das Instituições de Ensino Superior (IES), nas mais diversas especificidades, como o PIBID de Geografia, o PIBID de História, o PIBID de Letras, entre outros. Mas também, depara-se com o PIBID Interdisciplinar que, de modo geral, tem como objetivo a interação entre as disciplinas.

\section{Interdisciplinaridade}

Ao adentrar na temática da interdisciplinaridade e conhecer um pouco da sua história, pensa-se este tema como algo antigo, porém ele certamente é atual e desafiador. Esse tema traz diversas discussões acerca das relações existentes entre as disciplinas e os conhecimentos abordados pelo educador/profissional vinculados com a forma e com o que o aluno aprende.

Surgiu na Europa, principalmente na França e Itália, nos anos 60. Mas o movimento da interdisciplinaridade teve "a primeira produção significativa sobre o tema no Brasil" (FAZENDA, 2008, p. 24), nos anos 70, em que Hilton Japiassu publicou o livro Interdisciplinaridade e patologia do saber. Fazenda (2008) esboça um delineamento do processo de desenvolvimento dos estudos da interdisciplinaridade. Segundo essa autora, o tema foi estudado no Brasil em três períodos: no ano de 1970, 1980 e 1990.

Como o estudo ainda estava muito recente, os teóricos tiveram possíveis etapas de pesquisa, para então conseguir aderir uma relevância para o tema. $\mathrm{O}$ primeiro momento, em 1970, a preocupação foi conceituar interdisciplinaridade. Em 1980, o foco era criar um método interdisciplinar e, em 1990, o objetivo era estabelecer a interdisciplinaridade como um constructo teórico.

Em todos esses estudos, ainda segundo a autora referida, percebeu-se a complexidade do tema interdisciplinaridade pela sua grande abrangência e dificuldade de estabelecer um parâmetro único, conceitual e metodológico. Isso trouxe à tona a percepção da necessidade de formação de um novo profissional interdisciplinar, cuja capacitação passasse por um processo bem mais complexo.

A autora Fazenda, como pesquisadora e a partir dos trabalhos de Japiassu, entre outros, ateve-se ao estudo conceitual da interdisciplinaridade. Por conseguinte, como resultado das suas pesquisas, obteve a percepção que 
o professor interdisciplinar traz em si um gosto especial por conhecer e pesquisar, possui um grau de comprometimento diferente para com os seus alunos, ousa novas técnicas e procedimentos de ensino, porém, antes, analisa-os e dosa-os convenientemente. (FAZENDA, 2008, p. 31)

Para Fazenda, "o pensar interdisciplinar parte da premissa que nenhuma forma de conhecimento é em si mesma exaustiva. Tenta, pois, o diálogo com outras fontes do saber" (FAZENDA, 2002, p. 15). Esse tipo de pensamento, interdisciplinar, requer do educador uma nova atitude diante do conhecimento. Far-se-á necessária uma atitude de abertura diante dos saberes já construído, no sentido de compreensão e ampliação dos mesmos, de construção de ponte entre os diversos saberes, no tecimento de um conhecimento plural que é a base do entendimento interdisciplinar. Hilton Japiassu (2016, p. 3) afirma que

o grande desafio [...] neste início do século e milênio é contradição entre, de um lado, os problemas cada vez mais globais, interdependentes e planetários, do outro, a persistência de um modo de conhecimento ainda privilegiando os saberes fragmentados, parcelados e compartimentados.

Ou seja, existem ainda duas formas de compreender o conhecimento, a primeira delas é a presença de problemas mais gerais e dependentes uns dos outros, e a segunda delas é olhar para esses aprendizados de forma fragmentada, como se não existisse ligação entre eles. Logo, para esse autor, a solução seria, exaustivamente, buscar a totalidade do conhecimento, buscando uma visão global e sempre contextualizada do conhecimento, para que a compreensão seja, além de ampla, o objetivo a ser atingido.

Japiassu (2016) reafirma a necessidade urgente de um diálogo entre as disciplinas científicas, como base fundamental para a construção da interdisciplinaridade e da transdisciplinaridade. O primeiro obstáculo a ser transposto neste sentido seria uma nova atitude por parte do educador, enquanto questionador do que já está posto e legitimado no contexto social/educacional como imutável.

Todas as mudanças desafiam a ordem estabelecida. Criar algo novo, questionar o que já está instituído, são ações que exigem uma nova postura diante da instituição escolar e do mundo onde se vive. Japiassu (2016, p. 6) afirma que "o professor que não cresce, não estuda, não se questiona e não pesquisa deveria ter a dignidade de aposentar-se, mesmo no início de carreira", pois são esses educadores que podem transformar e mudar o modo de aplicar o conhecimento e fazer dessa interdisciplinaridade uma nova prática didática do meio escolar. 
Essa postura do professor, enquanto questionador e pesquisador, reveste-se da necessária e fundamental humildade intelectual que forma os verdadeiros cientistas, que são conscientes de sua pequenez e, por isso, despem-se de qualquer dogmatismo ideológico ou científico. Em consequência disso, o estudo da interdisciplinaridade se torna importante para a formação de um professor que quer mudar o que está posto e que quer fazer a diferença no senso crítico e aprendizado do seu aluno.

\section{O projeto}

Conscientes da importância da interdisciplinaridade no contexto escolar acima descrita, as acadêmicas de Letras e integrantes do PIBID Interdisciplinar, que tem por coordenadora uma professora também da UNESC, pensaram em um projeto que pudesse abranger uma gama de saberes disciplinares, além de conhecimentos de mundo, fazendo jus aos conceitos de integração e contextualização que o saber interdisciplinar exige ou sugere.

Para tanto, elaboraram um plano, com duração de oito encontros, intitulado "Cartas mágicas a 801". Tal projeto tinha por objetivo trabalhar com o gênero cartas, apresentando aos alunos informações de todo nível, como a história das cartas ao redor do mundo e no Brasil, os tipos de carta, as suas estruturas, vocabulário, preenchimento do envelope, história, utilização e valor cultural dos selos, bem como a leitura de cartas e as suas interpretações.

Além do mais, para garantir ao projeto uma ludicidade bem-vinda, foi aliado ao seu núcleo - cartas - a temática do universo de Harry Potter, criado pela escritora britânica J.K. Rowling. O bruxo recebe, logo no primeiro livro, uma carta da Escola de Magia e Bruxaria de Hogwarts convidando-o a fazer parte do corpo discente e, da mesma forma, os alunos da escola Pascoal Meller em Criciúma, Santa Catarina, também a recebem.

Outrossim, os educandos também ganharam uma fita cuja cor representava a casa a qual estavam destinados (amarela para Lufa-Lufa, vermelha para Grifinória, azul para Corvinal e verde para Sonserina, todas retiradas dos livros de Rowling). O objetivo disso era dividi-los em equipes, para que assim pudessem participar da "Copa das casas". Dessa forma, cada dia, após a exposição e discussão dos conteúdos, os alunos realizavam uma atividade de retomada dos conhecimentos, em que os vencedores de cada tarefa pontuavam para suas respectivas casas.

A justificativa para a referida dinâmica de pontuação baseia-se no fato de que, de certa forma, os alunos interessam-se mais em realizar as atividades, já que contarão pontos para as Revista Interinstitucional Artes de Educar. Rio de Janeiro, V. 7, N. 1 - pág. 586-596 janeiroabril de 2021: "Pedagogias Vitais: Corpo, Desejo e Educação" DOI: 10.12957/riae.2021.55181 
suas equipes. Além disso, tal forma de aprendizado é lúdico e garante a participação de todos no processo de aquisição e produção de conhecimentos. Portanto, ao final do projeto, apenas uma casa seria a campeã - um estímulo a mais para o envolvimento, que, nesse caso, é sustentado por uma competição saudável.

\section{Primeiro encontro}

O primeiro encontro, em que o projeto foi iniciado, foi essencial para a visualização do restante as aulas. Nesse dia, os alunos tiveram contato com as bolsistas, com o método que se valeria para o decorrer das aulas e, principalmente, com o tema que elas abordariam em suas aulas, o gênero carta. Para que os alunos não participassem de todo esse universo sem o conhecê-lo, a aula sucedeu de forma a apresentar um trecho do filme Harry Potter e a Pedra Filosofal, principalmente trechos em que aparecia o envolvimento direto com a carta, já que o personagem principal recebe uma carta de admissão da escola de Hogwarts.

A partir desse detalhe do filme, as acadêmicas tiveram a ideia de utilizar a mesma carta de admissão como introdução ao projeto, separando, assim, os alunos em quatro casas, para que fosse posto em prática a ideia de uma atividade lúdica em meio ao aprendizado, visto que, de acordo com Correia e Bento $(2014$, p. 3) "mediando à construção do conhecimento através do lúdico, pode-se alcançar uma educação de qualidade e que consiga ir ao encontro dos interesses e necessidades da criança".

\section{Segundo encontro}

No segundo encontro já iniciaram as abordagens sobre o tema escolhido. As acadêmicas fizeram uso de handout para que os alunos tivessem um registro escrito do que estava sendo discutido e que, por meio desse, pudessem acompanhar o andamento e linha de explicação e conversa.

O subtema dentro do tema maior abordado pelas bolsistas foi a origem da carta nos mais diversos países do mundo, bem como a origem da escrita e a forma como era realizada. Assim, os educandos tiveram contato com imagens e curiosidades como a utilização do pombo correio, já que alguns países faziam uso antigamente, e a argila, objeto utilizado como 
uma espécie de papel, já que este ainda não existia. Aprenderam também sobre os tipos de cartas, tanto as formais quanto as informais.

De acordo com as acadêmicas, o que chamou mais atenção dos educandos foi a questão do pombo-correio, animais muito marcantes na história das cartas. De acordo com Darwin (apud MARTINS, 2012, p. 98), o pombo-correio era "notável pelo seu sentido de orientação, pelo vôo rápido e pela capacidade de percorrer grandes distâncias (que chega a alguns milhares de quilômetros)", ajudando na entrega de cartas. Ao final da aula, participaram da sua primeira atividade para o campeonato das casas.

\section{Terceiro encontro}

No terceiro encontro o foco estava concentrado ainda na historicidade da carta, mas, dessa vez, no contexto brasileiro, de forma a apresentar o uso do primeiro registro histórico em que as terras brasileiras foram citadas. Por isso, os alunos leram e interpretaram um trecho da carta de descobrimento do Brasil, de Pero Vaz de Caminha ao rei de Portugal, discutindo sobre aspectos como a história do "descobrimento", a descrição do índio e a literatura de informação. Além disso, os alunos conheceram alguns outros textos da literatura brasileira em que o índio foi mencionado.

Com relação a essa aula, as acadêmicas tiveram o cuidado com a expressão “descobrimento do Brasil”, já que existem historiadores e teorias que afirmam que, como já tinham índios morando no Brasil, não foi especificamente um descobrimento, mas sim um "achamento". Ao final, realizaram atividades que também somou pontos à competição das casas.

\section{Quarto encontro}

O quarto encontro teve o intuito de familiarizá-los com a estrutura da carta. O handout, ainda utilizados pelas bolsistas para o melhor acompanhamento por parte dos alunos, dessa vez, foi estruturado de maneira que a explicação estivesse em forma de carta. Assim, após aprenderem pronomes de tratamento, saudações e fechamentos, além da forma visual de como toda a carta formal deve se estruturar, tiveram de fazer uma carta para validar pontos para a equipe.

Revista Interinstitucional Artes de Educar. Rio de Janeiro, V. 7, N. 1 - pág. 586-596 janeiroabril de 2021: "Pedagogias Vitais: Corpo, Desejo e Educação" DOI: 10.12957/riae.2021.55181 
O tema da produção teve vínculo com a última aula, de maneira que eles tiveram de escrever sobre "o primeiro contato com uma escola", narrando qual a primeira impressão que tiveram. Partiram do pressuposto de que eles não conheciam esse ambiente, assim como Pero Vaz de Caminha não conhecia o Brasil.

\section{Quinto encontro}

No quinto encontro, com a aproximação do Halloween e em concordância com a temática de bruxos presente em Harry Potter, as acadêmicas pensaram em trazer um pouco da cultura norte-americana e brasileira, expondo para a sala de aula uma contação de lendas urbanas, em volta de uma fogueira produzida pelas próprias pibidianas. Cada casa da competição foi avisada de antemão para trazer uma história de terror, contando para os demais colegas em volta da "fogueira".

Além disso, as acadêmicas produziram um conto fantástico original relacionando as cartas com fenômenos sobrenaturais. Com o sucesso de tal atividade, o grupo foi convidado para reproduzir a contação de lendas urbanas para o restante da escola no evento de Halloween realizado pela direção. Dessa forma, várias turmas tiveram a possibilidade de ouvir lendas típicas contadas Brasil afora.

\section{Sexto encontro}

Dando seguimento ao projeto, os alunos que, até então, tiveram contato com a parte interna da carta, como a estrutura, o conteúdo, a função etc., conheceram a parte externa das correspondências. Aprenderam, portanto, como preencher um envelope, como enviar uma carta, qual a função do selo, além de curiosidades interessantes a respeito deste.

Como forma de pontuação, as acadêmicas realizaram um jogo de forca com as palavras "Onepennyblack", nome do primeiro selo inventado, na Inglaterra. Além disso, cada aluno teve que produzir o seu próprio selo, levando em consideração as características que ele precisava apresentar. Receberam gabaritos, em que puderam desenhar suas próprias criações, e ficaram cientes de que o melhor selo da turma - eleito pelos alunos da UNESC, que votariam no que mais gostaram - ganharia os pontos para sua casa. 


\section{Sétimo encontro}

A sétima e penúltima aula foi mais de leitura do que de exposição. Os alunos receberam cartas de fãs de Harry Potter, de diversas nacionalidades, escritas para um concurso. As cartas estavam reunidas no livro Cartas ao Harry Potter, e os alunos fizeram a leitura de três delas, de diferentes conteúdos e partes do mundo, sendo uma do Brasil, uma das Filipinas e outra da Califórnia.

Depois de cada leitura, foi discutido mais um pouco sobre a estrutura que as crianças fizeram uso, além de fazer a interpretação sobre o que estava no conteúdo da carta, associando à forma que foram escritas. Discutiu-se a respeito da realidade de cada criança que enviou a carta, contrastando as suas respectivas vidas e sobre o que pediam ao Harry. Além disso, foi realizado o amigo secreto de cartas, sendo que cada aluno tirou o nome de um colega, tendo de escrever para seu amigo, como forma de encerramento.

\section{Oitavo e último encontro}

No último encontro foi realizado o amigo secreto de cartas, que tanto as três pibidianas quanto a supervisora participaram, em um momento de muita descontração e clima de despedida. Os alunos receberam das acadêmicas um selo feito com uma foto da turma, realizada alguns dias antes, como forma de recordação.

Realizou-se, também, um sorteio do livro Cartas ao Harry Potter, utilizado anteriormente na aula, e foi anunciada a casa vencedora do campeonato, Grifinória, presenteando os integrantes com uma caixa de bombons cada. Para encerrar, as alunas agradeceram a experiência encantadora que puderam vivenciar no projeto, e despediram-se de todos.

\section{Conclusão}

No decorrer deste artigo, foi observado o quão importante se faz o ensino dos diferentes saberes como pontes que podem ser conectadas. O estudo da interdisciplinaridade, então, se faz eficiente para a formação do professor e do aluno. Esse campo de estudo da 
interdisciplinaridade é bastante novo e está sofrendo atualizações ao longo dos anos, se tornando cada vez mais importante a sua inserção dentro das salas de aulas atuais.

As acadêmicas, no decorrer do projeto, perceberam com a prática interdisciplinar a relevância do assunto para o meio de ensino-aprendizagem, tanto do professor como dos alunos. A experiência pela qual participaram foi de extrema importância para sua prática docente, formação acadêmica e profissional, além de terem conhecido a realidade escolar básica antes mesmo do estágio, angariando um rico aprendizado com a vivência e com os alunos.

Em suma, o ensino da interdisciplinaridade é uma discussão muito importante para todos os profissionais das áreas de licenciatura, pois, desse modo, proporcionará à prática do professor e para os seus alunos um conhecimento plural e diversificado, criando pontes para os saberes. Sabe-se, entretanto, que a interdisciplinaridade é um horizonte difícil, muitas vezes, de ser alcançado. O que não se deve é desistir dessa prática tão rica e produtiva para a formação educacional e crítica dos alunos.

\section{REFERÊNCIAS}

BRASIL. Capes. Ministério da Educação. PIBID: Programa Institucional de Bolsa de Iniciação à Docência. 2008. Disponível em: <http://www.capes.gov.br/educacaobasica/capespibid >. Acesso em: 15 mar. 2017.

FAZENDA, I. C. A. Interdisciplinaridade: Historia, teoria e pesquisa. Campinas, SP: Papirus. 2008, 15 ed.

FAZENDA, I. C. A. Interdisciplinaridade: um projeto em parceria. São Paulo: Ed. Loyola. 2002. 5 ed.

JAPIASSU, H. O Sonho Transdisciplinar. DESAFIOS, v. 3, n. 1, p. 3-9, set. 2016. Disponível em <https://sistemas.uft.edu.br/periodicos/index.php/desafios/article/view/2555>. Acesso em: 01 fev. 2017. doi: https://doi.org/10.20873/uft.2359-3652.2016v3n1p3.

BENTO, R., \& CORREIA, L. A importância do lúdico para a aprendizagem na educação infantil. Revistas Saberes, 1, 20, 2014. Disponível em: <https://unijipa.edu.br/wpcontent/uploads/sites/2/2019/02/54_218.pdf> Acesso em: 19 de junho de 2020.

MARTINS, R. de A. M. A origem dos pombos domésticos na estratégia argumentativa de Charles Darwin. Filosofia e História da Biologia, v. 7, n. 1, p. 91-116, 2012. Disponível em: $<$ http://www.abfhib.org/FHB/FHB-07-1/FHB-v07-n1-06.html $>$ Acesso em: 25 de março de 2017. 
${ }^{\text {i }}$ Formada no curso de Letras - Habilitação em Língua Portuguesa pela Universidade do Extremo Sul Catarinense (UNESC). Mestranda em Letras, com área de concentração em Teoria da Literatura no Programa de PósGraduação da Pontifícia Universidade Católica do Rio Grande do Sul (PUCRS). Tem interesse nos estudos de Literatura, leitura e formação de leitores. Rio Grande do Sul - Brasil. ORCID iD https://orcid.org/0000-00022270-7416

${ }^{\text {ii }}$ Formada no curso de Letras - Habilitação em Língua Portuguesa da Universidade do Extremo Sul Catarinense (UNESC), com período sanduíche (2018/01) na Universidade do Porto, Portugal. Tem interesse em temas sobre aprendizagem de língua estrangeira, ensino de língua e de literatura. Brasil. ORCID iD https://orcid.org/00000002-6846-9863

iii Graduada em Psicologia pela Universidade Federal de Santa Catarina (UFSC), em 1986. Formada em Letras Habilitação em Língua Portuguesa pela Universidade do Extremo Sul Catarinense (UNESC), em 2018. Atualmente, cursando Letras - Habilitação em Inglês na UNESC e Mestranda em Educação (UNESC), na linha de pesquisa em Educação, Linguagem e Memória com interesse no estudo da Literatura, sua recepção e efeito na formação humana. Santa Catarina - Brasil. ORCID iD https://orcid.org/0000-0002-2825-0322

iv Resumo da Biografia: Formada em Letras - Português/Inglês pela Universidade do Sul de Santa Catarina UNISUL. É mestra em Ciências da Linguagem, também pela UNISUL. Atualmente, é Assessora Pedagógica da Diretoria de Ensino de Graduação da Unesc. Leciona disciplinas da área da Linguística, bem como de Sintaxe e de Produção Textual. É também professora de Estágio Supervisionado de Língua Portuguesa e coordenadora de dois Projetos de Extensão: Sala de Leitura: formando leitores literários e transformadores; e Letramento como estratégia para a autonomia. É Coordenadora do Subprojeto Interdisciplinar do PIBID. Também leciona Produção e Interpretação de Texto em diversos outros cursos desta mesma universidade. Desde fevereiro de 2012 tem atuado como formadora em Cursos de Formação Continuada - Ensino Fundamental e Médio. E, desde 2014, é Professora titular da Rede Estadual de Ensino. Santa Catarina - Brasil. ORCID iD https://orcid.org/0000-0001-9208-9388

${ }^{v}$ Formada em Letras - Português/Inglês pela Universidade do Extremo Sul Catarinense (UNESC) e especialista em Metodologia e Prática Interdisciplinar do Ensino pela FUCAP. Foi professora supervisora do PIBID Interdisciplinar. Tem interesse em temas como Educação, Práticas Pedagógicas de Ensino, inclusive interdisciplinares e Análise Linguística. Brasil. ORCID iD https://orcid.org/0000-0001-6657-8161 